DOI: $10.20472 / S S .2020 .9 .1 .006$

\title{
BARI SHEJ CASE STUDY - MENTORING PROGRAM TO REDUCE SCHOOL DROP-OUT RATES FOR TEENAGE ROMA GIRLS
}

\section{EMESE PUPEK PHD}

\begin{abstract}
:
The programs for disadvantaged Roma (Gipsy) girls are aimed at catching up, talent development, and integration into the labor market and society. The Bari Shej (Big Girl) project aims to reduce the school drop-out rate of disadvantaged Roma girls and to increase their chances of further education through a mentoring system. The Bari Shej case study is an evaluation of a mentoring system, the exchange of practical experiences by analyzing the views of participants and stakeholders.

The research included an analysis of the monthly data reporting of the mentors, with focus group studies. Mentees' opinions were collected through a questionnaire. A questionnaire and in-depth interviews were conducted with stakeholders from the wider environment. The organizations involved in the project filled out a template for structured collection of good practices. In-depth interviews were conducted with the decision makers defining the framework of the project. Through document analysis, various scientific results, mentoring methods, statistical indicators and trends were analyzed.

This study presents good practices that have been implemented in Hungary by a number of non-governmental organizations under the coordination of an authority with the support of the European Union.
\end{abstract}

\section{Keywords:}

Hungarian Roma teenage girls, school drop-out, mentor system, best practice, handicap compensation

JEL Classification: 124, J13, L31

\section{Authors:}

EMESE PUPEK PHD, Hungarian Educational Authority, Hungary, Email: drpupekemese@gmail.com

\section{Citation:}

EMESE PUPEK PHD (2020). Bari Shej Case Study - Mentoring Program to Reduce School Drop-Out Rates for Teenage Roma Girls. International Journal of Social Sciences, Vol. IX(1), pp. 95-112., 10.20472/SS.2020.9.1.006 


\section{Introduction}

When a teenage Roma girl comes to the conclusion that "I really thought it could be realized, our dreams could come true." - this is a real evaluation of the mentoring program. This is what happened in Hungary under the Bari Shej program.

\subsection{The Roma background in Europe}

Roma people are the biggest ethnic minority in Europe. There are an estimated 11-15 million Roma individuals in the European Region. The number of Roma is highest in Romania (approximately $1.2-2.5$ million, $8.3 \%$ of the population) and Bulgaria $(700,000-800,000,10.3 \%$ of the population), while in Hungary the Roma population accounts for approximately $7.05 \%$ $(400,000-1,000,000)$ of the total population, and their number is continuously increasing. (European Commission, 2011)

Many of the estimated 11-15 million Roma in Europe face prejudice, intolerance, discrimination and social exclusion in their daily lives. They are marginalised and live in very poor socioeconomic conditions. European Union Agency For Fundamental Rights (FRA) surveys undertaken in 2011 and 2016 also found that prejudice, intolerance and discrimination affect a large proportion of Roma living in the European Union (EU) member states, most of whom are EU citizens. (FRA 2017)

Several European governments declared the years 2005-2015 to be the Decade of Roma Inclusion. Signing the Declaration of the Decade of Roma Inclusion, the Prime Ministers of Bulgaria, Croatia, the Czech Republic, Hungary, the Former Yugoslav Republic of Macedonia, Montenegro, Romania, Serbia and Slovakia kicked off the Decade of Roma Inclusion 2005-2015. Albania, Bosnia and Herzegovina and Spain joined later in 2008, while Slovenia, Moldova, Norway and the United States participated in the initiative as observers. The Decade of Roma Inclusion 2005-2015 was an unprecedented political commitment by European governments to eliminate discrimination against Roma and close the unacceptable gaps between Roma and the rest of society. The Roma Decade focused on the priority areas of education, employment, health, and housing, and committed governments to take into account the other core issues of poverty, discrimination, and gender mainstreaming. (Declaration 2005)

Inspired by the Decade of Roma Inclusion, on 5 April 2011, the European Commission adopted the EU Framework for National Roma Integration Strategies up to 2020. EU Member States were requested to prepare or revise their national Roma integration strategies and presented them to the Commission by the end of December 2011. In spring 2012, ahead of the annual Roma Platform meeting, the Commission assessed these national strategies and reported to the European Parliament and to the Council about progress. 
The European Commission published an evaluation of the EU Framework for National Roma Integration Strategies (NRIS) up to 2020 on 4 December 2018. The evaluation assessed the EU framework and how it mobilised other European policy, legal and funding instruments for Roma inclusion. (European Commission 2019)

In education and the fight against discrimination and antigypsyism most measures are targeted for Roma. Most Member States (MS) invest in measures to reduce early school-leaving (18 MS). The next most frequently used measures include: considering the needs of individual pupils in cooperation with their families (14MS); increasing the access to, and quality of, early childhood education and care (13 MS); and encouraging Roma participation in - and completion of secondary and tertiary education (11MS). Efforts are also made to fight school segregation; use inclusive teaching methods; and develop skills adapted to labour market needs (12 MS each). Member States most often opt for measures to improve educational attainment: fighting drop-out; encouraging transition to - and completion of - secondary and tertiary education; or providing support to compensate for educational gaps, or material disadvantage. (European Commission, 2019)

In addition to education, other areas appear in European Roma strategies and analyzes. In Serbia the practice of child marriage among the Roma was found to be most common among girls who lived in poorer households, who had less education, and who lived in rural locations. Hotchkiss (2016) ) Other information is available from Serbia on segregation and fertility for marginalized Roma ethnic minority. (Battaglia - Chabé-Ferret - Lebedinski 2017) Health of Roma children in Hungary. (Sárváry 2019) Other study about health differences at birth between Roma and non-Roma children in Hungary (long-run trends) has found that Roma mothers have been twice as likely to give birth to babies with low birth weight and before the 37th week. Standard decompositions show that at least 80 percent of the gaps are explained by socioeconomic factors, and education alone explains more than half. (Hajdú - Kertesi - Kézdi 2019) Or decomposing gaps between Roma and Non-Roma in Romania. (Rauh 2018) How Roma women are fighting to improve their own living conditions and those of their people by organizing at the grassroots level. (Aiello, E.; Amador-López, J.; Munté-Pascual, A.; Sordé-Martí, T. 2019)

In Bulgaria there was a survey to study the current attitudes that Roma communities hold regarding an existing Roma tradition - the practice of keeping a girl out of school in order to preserve her virginity. (Kyuchukov 2011) Numerous further studies were conducted on Roma society. There is also an analysis on the subject that reviews studies on Roma and education, covering the period 1997-2016. (Lauritzen - Nodeland 2018)

In 2019, there are still $68 \%$ of Roma in Europe who leave education early, while the Europe 2020 early school leavers target is $10 \%$. In addition only $18 \%$ of Roma children transit to higher levels of education and the absenteeism and early-school leaving rates of Roma are significantly higher than for other categories of pupils. (Factsheet 2019) 
Educational equality between Roma and non-Roma is hence perceived both as a value in itself and as a means to offer equal chances in other spheres of life. No other policy area has received as much political attention. (Brüggemann - Friedman 2017)

Among other things, the European Commission has highlighted the priority to be addressed: target Roma girls, their parents and teachers to fight gender stereotypes and reduce early schoolleaving. (European Commission, 2019)

\subsection{About the background of the Bari Shej program}

Drop-out, early school leaving are a serious problem for affected children / young people, their families and the whole of the society not only in Hungary, but all over the world. Early school leavers do not acquire the skills they need to succeed in the labor market, thus jeopardizing their own future, because without proper education, job opportunities are much narrower, if at all. Research on early school leaving has identified a number of reasons, including the close relationship between the student's and his / her family's social status, financial status and learning relationship.

The Roma population is more exposed to early school leaving, with the greatest disadvantages for Roma girls.

In Hungary, the proportion of Roma with tertiary education is far below that of the general population. According to the Census data of the Hungarian Central Statistical Office of 2001 and 2011 , the proportion of people with tertiary education in the total population aged 25 and over was $12.6 \%$ and $19.0 \%$, respectively, and $0.37 \%$ (2001) and 0.83\% (2011) among Roma. According to the 2016 micro-census, nearly $80 \%$ of Roma over the age of 14 have no more than primary education and $17 \%$ have not completed primary school. $6.9 \%$ have a high school qualification, compared with $32 \%$ of the population. Out of every 100 Roma, only one has a diploma, while the overall population is twenty times more likely to have a university degree. (Hungarian Central Statistical Office 2018) 


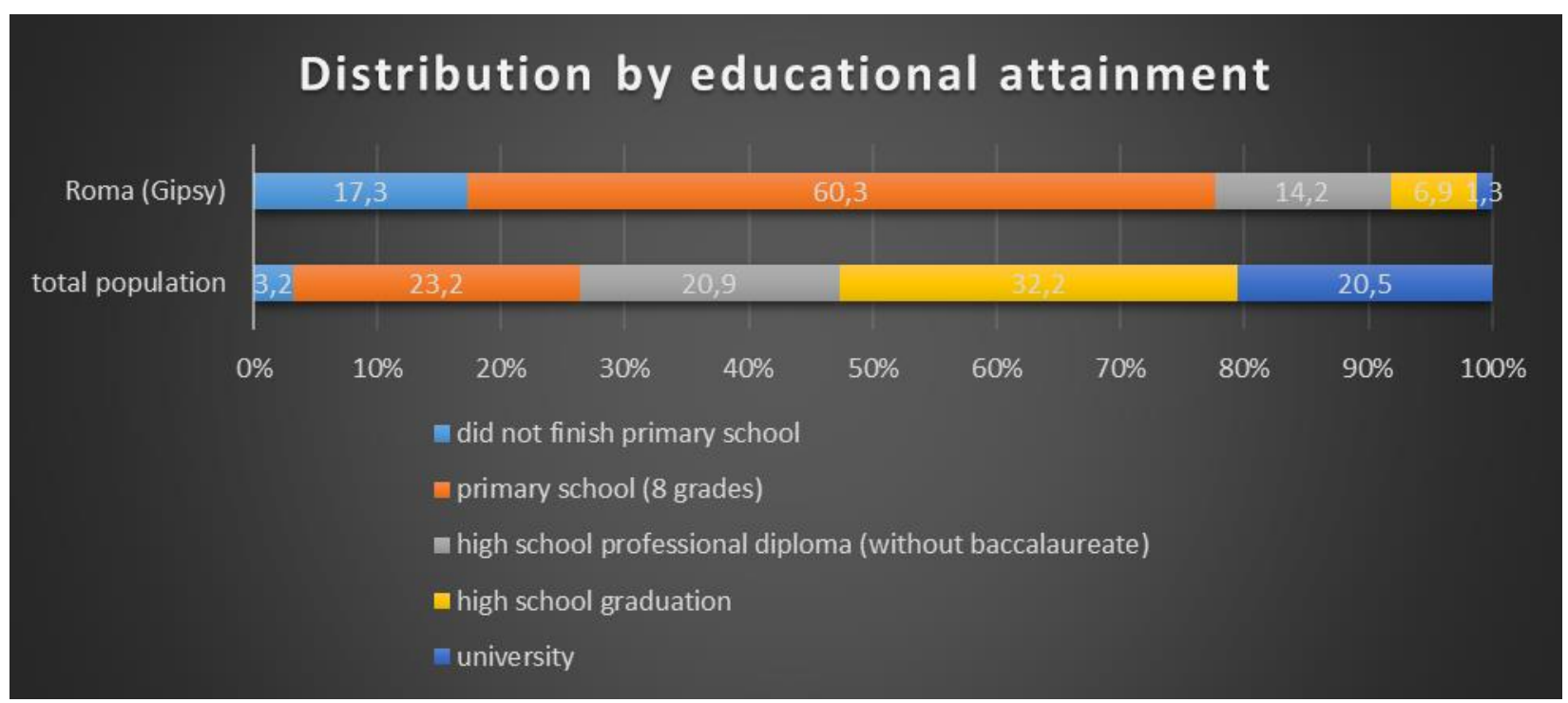

1. figure: Distribution by educational attainment, Source: Author, Based on data from Hungarian Central Statistical Office

In Hungary, women of Roma origin can be considered as a cumulatively disadvantaged group, even within the Roma population. One of the main sources of vulnerability of Roma women is their low level of education and the resulting disadvantage in the labor market. It is a priority to support them from the earliest age, by focusing on increasing their chances at school and on the labor market. The employment rate of Roma women is $15.9 \%$. Overall, the employment rate of non-Roma women is two and a half times higher than that of Roma women. The fertility rates of Roma women are higher, which also results in two and a half times the inactive earners compared to the majority society. (Statisztikai Tükör, 2015/82)

The implementation of the "Hungarian National Social Convergence Strategy II." Point 7 of the Government's Action Plan for the years 2015-2017 states that targeted measures should be taken to prevent uneducated early school leavers and special attention to be given to preventing unskilled Roma girls.

The European Parliament has called on Member States to develop programs to prevent Roma girls from leaving school without qualifications. The Hungarian Government has supported several of these programs, including the Bari Shej program.

In Bari Shej program, cooperating organizations include associations, foundations, national minority self-governments, church-maintained organizations, non-profit organizations, sports associations, and public education institutions. Each organization had experience in working with poor, disadvantaged children.

The implementation was extended to all regions of the country except the capital region. 
Nearly $\$ 10$ million was distributed among the organizations to carry out the project.

The Hungarian Educational Authority provides professional and methodological support to project implementation organizations.

The Hungarian Educational Authority is a budgetary organization established by the Hungarian government in 1999, core activity: tasks related to public administration and higher education sector administration; authentic public education and higher education registration tasks; operating an educational record; official duties; professional control, measurement and evaluation tasks.

The Roma girls are the most vulnerable group in the Hungarian society. The priority is to ensure that Roma girls do not regard early family formation as the only way forward rather than continuing education; it is important to be aware of the opportunities for further education. By becoming motivated to learn, they are more likely to catch up, find a job and make a living. It is important to develop self-knowledge and social competences. They need to know themselves and their own culture and that of their peers. So the purpose of mentoring is to bring about a shift in attitudes and thinking that will motivate them to become adults who are consciously responsible for themselves and their families.

A mentoring system at local level and with an almost daily presence can help to reduce the dropout rate of disadvantaged girls, especially Roma girls, and increase their chances of further education. Mentoring can be used to enhance the learning motivation and learning behavior of girls at risk of dropping out, to help them start a family and start having children later in life, to improve their health and to reduce their chances of becoming a victim.

Between April and September 2017, the Hungarian Educational Authority conducted a needs assessment to explore the benefits of mentoring in order to provide the highest possible level of professional support to Bari Shej project winners.

The Hungarian Educational Authority has produced a mentoring manual to support mentoring activities, which outlines the topic in a scientific way, while providing a number of practical tips. Not only are the authors immersed in the literature, they also share their practical experiences in a useful way.

The Hungarian Educational Authority provided complex background support consisting of: methodological and professional support for mentors; encouraging and supporting content partnerships between organizations involved in the project - sharing of good practices, transfer of experience; and use, alignment and improve the traceability of the results and experiences of the former programs to increase disadvantage compensation outside the school system.

\section{Method of analysis of Bari Shej's mentoring system}

\subsection{Source of data used for evaluation}

87 NGOs (local minority self-governments, social and child welfare institutions, and civil and church organizations) participated in the project, with 438 mentors mentoring nearly 2,000 Roma girls in the 10-18 age group.

The implementation of the project was evaluated on the basis of data collected by the Hungarian Educational Authority: monthly mentor data, focus group studies, anonymous questionnaire for mentees, anonymous questionnaires for school principals and class leader teachers, and good practices uploaded by program leaders, stakeholders's interviews and documentum analysis. 
Mentors uploaded monthly information on mentoring activities to an electronic interface operated by the Hungarian Educational Authority. Mentors kept a log of the mentoring process. The main events of the diary were also recorded by the mentor in the mentoring system of the project's Internet interface, taking into account the protection of personal data.

Mentors uploaded a total of 177,220 individual and 20,012 group mentoring data. The lists have always reached $97 \%$ to $98 \%$ of the month, which means that the mentors have fulfilled their administrative obligations.

The vast majority of mentors worked with 5 mentees at a time.

Most mentoring takes between 40 and 65 minutes. There was also individual mentoring between 0-5 minutes and 285-300 minutes.

The anonymous questionnaire for mentees was distributed to all participants in the project. We processed 431 responses, which is nearly 20 percent of those affected. 96 people responded to the questionnaire of school principals and class leader teachers.

We have prepared a template for collecting good practices and getting to know more details, which was fill out by half of the project implementation organizations.

In-depth interviews were conducted with the decision makers defining the framework of the project; stakeholders and several mentors.

The project promoters had to select girls who were at risk of dropping out. These may include: failure of subjects, repetition of the year, many absences, presence of drop-outs in case of more siblings, low education of parents - up to 8 grades, private student status, housing disadvantages of the family and poor financial conditions.

The project mentors provide individual and group mentoring. The personal support of mentors provides an opportunity to stimulate learning and support the family. During mentoring, selfawareness, prevention and disadvantage compensation are realized. Personal examples of mentors, regular group workshops, cooperation between professionals, self-awareness training, prevention activities and career guidance activities all contribute to the achievement of the project objectives.

The mentor and the girl met at least twice a week. Family mentoring was on a regular basis as needed.

NGOs may apply for a maximum implementation period of 24 months.

\subsection{Professional support for mentors}

The purpose of mentoring is to develop self-knowledge, develop a realistic vision, career orientation, communication skills, learning support, social competences, career development, cultural mediation, offering leisure activities and many other activities related to these areas.

The previous ones came through many conversations, playful development, and the mentors kept motivating the girls, providing opportunities for help and request, collaboration, group building, and experience sharing. 
The mentors received professional support for their work in the form of mentor preparation, mentor manual, workshop work. These opportunities were found to be particularly useful in workshops, where good practices were exchanged.

The focus of mentor training was on sensitization, while the workshop sessions provided a wealth of useful experience, learning from each other, and learning about each other's good practices, and subsequently utilizing the knowledge gained in the local context. The mentoring handbook summarized the basic concepts, roles and methodology of mentoring.

The mentors asked experts to help the girls' development through lectures and group sessions, and to discuss topics that they experienced during their lives and receive professional advice. These meetings help mentees to orient themselves in certain life situations, choose the right behavior, and develop their knowledge.

Most often in the fields of health, self-knowledge and prevention, psychologist, nurse, doctor, special education teacher, social worker, priest, mental health, family assistant, romologist and career counselor, as well as art therapist, police crime prevention consultant and employment consultant were involved. In addition to the above, self-defense trainers and drug prevention lecturers met the girls. Sports coach, dance instructor, clothing and cosmetics consultants were also invited.

In order to make the project more effective, the mentoring organizations have partnered with various organizations to work together on several joint programs and to support the implementation of the Bari Shej program.

In particular, NGOs sought contact with municipalities in order to inform decision-makers and enable them to disseminate the results of the project and to sensitize the local community. In addition, several municipalities have provided venues for workshops and events organized as part of project implementation.

Multiple co-operation has taken place with minority self-governments, such as joint Roma days, or supporting the project with cooking, basic materials and professional assistance.

For example, girls were invited to theatrical performances with the help of family associations, foundations and art groups. To get the girls to organized programs, they had to be transported. Several NGOs have been supported by local labor market actors for this purpose.

Mentoring organizations have been in contact with higher education institutions and Roma colleges due to their career orientation. The services of the health visitors and the police were also helpful.

Mentors less and less indicated whether they needed help (68\% in autumn 2018 and 40\% in summer 2019) as the project progressed. Among those who did, the most frequent responses were to methodological and family involvement assistance.

The mentors were able to take advantage of the supervision, reporting it on a monthly basis. According to the total figures, less than 16 per cent received supervision and more supervision was conducted towards the end of the program.

In addition to the supervision, the mentors' work was facilitated by group case discussions, which were held by organization. Based on the total data, the majority of mentors (61\%) participated in the case discussion. Which organizations held case discussions were usually held monthly. By the second half of the project implementation, the number of mentors who reported having a case discussion tripled. So this method proved to be useful. 


\section{Results of Bari Shej's mentoring system}

\subsection{Mentoring activities}

Mentoring was done on the basis of a preliminary plan, the mentoring plan was tailor-made. Mentors kept a log of the mentoring process.

Individual and group mentoring are suitable for mentored girls to discuss their personal problems, learning difficulties, and seek help and advice.

During individual mentoring, only the mentor and the mentee are present.

Among the main forums for individual mentoring, face-to-face meetings are most common (58\%), complemented by electronic (23\%) and, to a lesser extent, telephone (19\%) forms of mentoring. Electronic devices include email, Facebook, Skype, Viber, WhatsApp, etc. use. These proportions do not show any significant change in the different phases of the project implementation, be it autumn or summer.

Individual mentoring focused on life coaching, behavioral culture and communication followed by social skills, subject preparation, mentee motivation enhancement and career guidance.

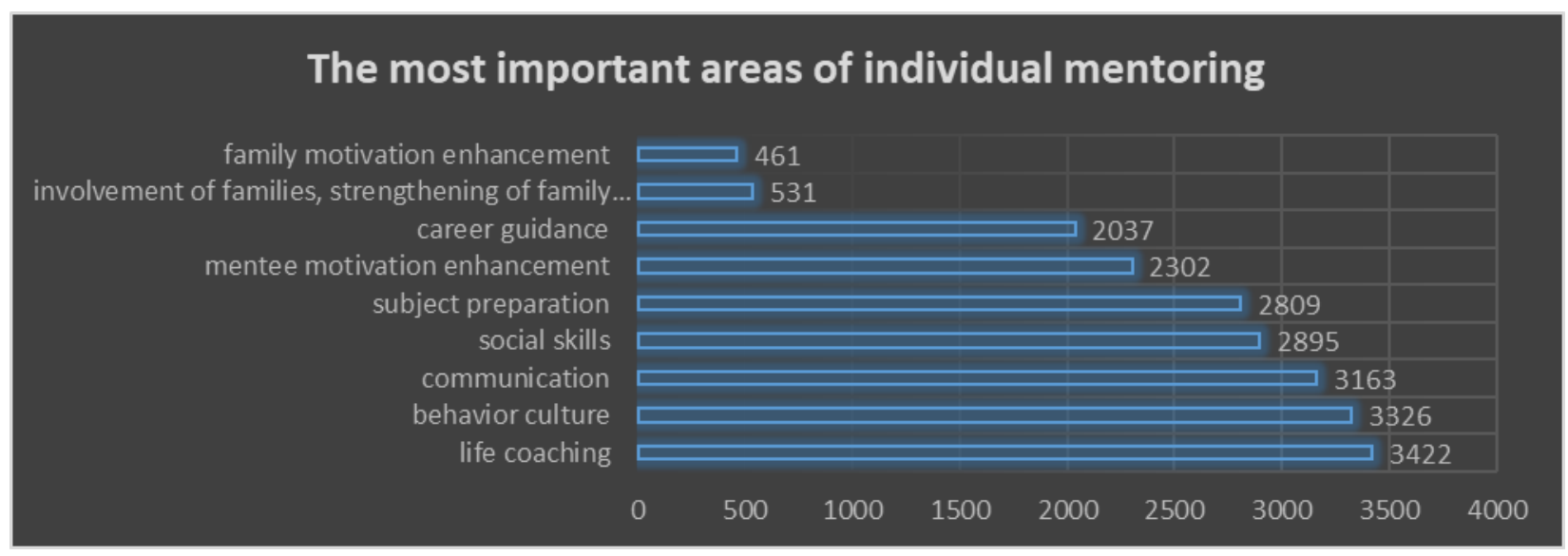

2. figure: The most important areas of individual mentoring (all data) Source: Author, Hungarian Educational Authority

Mentors provide both individual and group mentoring. It means that more people are involved in group mentoring and that they establish relationships not only with the mentor but also with the group members. As a member of a group, mentees are also able to develop their social relationships, have a better understanding of interpersonal and intergroup processes, influence, and a sense of belonging (group cohesion) can be positive.

Based on the total data, most group mentoring was done on self-knowledge topics, followed by cultural issues with the same weight as family and female roles, but slightly behind, but still quite popular, was health and a healthy lifestyle.

Preventing victimization was the second most popular topic at the start of mentoring. 


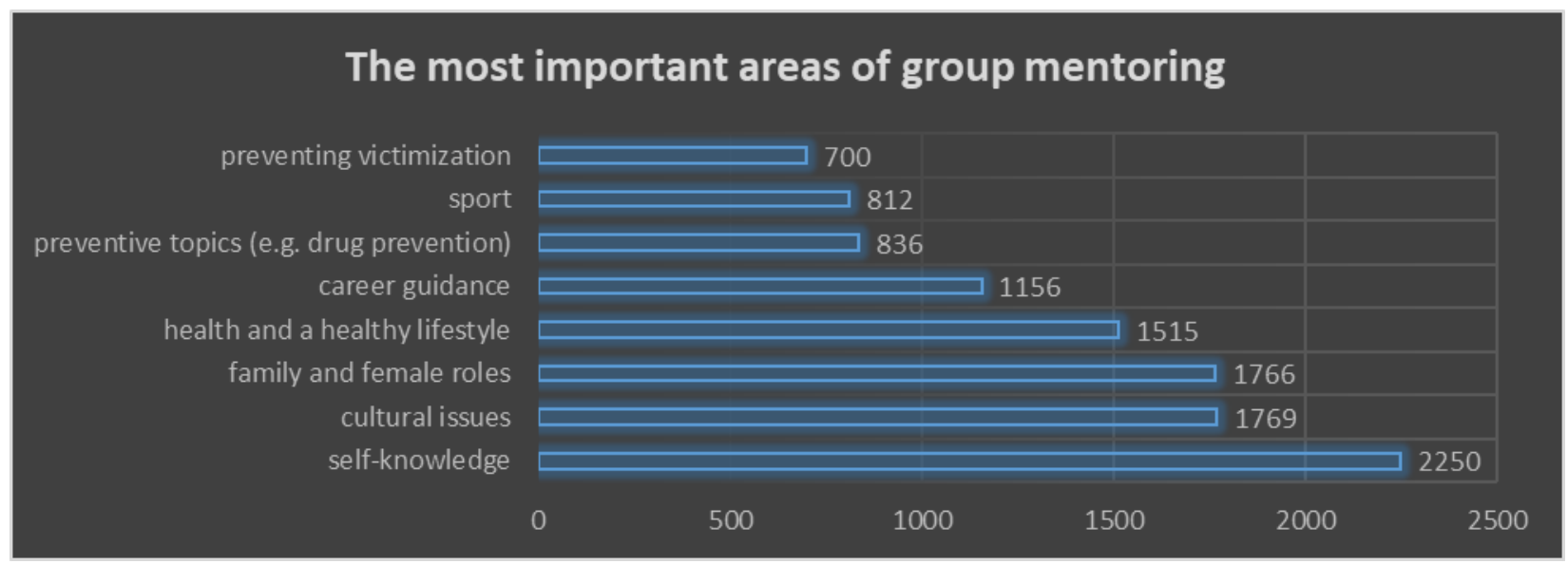

3. figure: The most important areas of group mentoring (all data) Source: Author, Hungarian Educational Authority

The major themes of group mentoring have changed from time to time. Comparison of the data reveals that prevention-related topics, such as drug prevention, have become more common, whereas over time, self-knowledge activities have been replaced by family and female roles.

Mostly career guidance sessions, prevention sessions, self-awareness training, and pre-victim media literacy training were held. Excursions, camping, sporting activities, self-defense sports, creative activities, cooking, gypsy dancing, cultural events, theater visits, tours, and healthy lifestyle programs were organized for them to spend their free time.

The above has broadened the horizons of the girls, improved their literacy and social skills, experienced the experience as a team, and has known and experienced opportunities that will influence their lives. They traveled to many cities, to many events that they could not see or experience without the program. Through this project, the communication and social skills of the mentored girls were greatly improved, and their speaking skills, which were well used in their learning and social relationships, improved.

In dealing with girls, many topics that were unavailable or unwilling to discuss within the family emerged. Particularly with regard to sexuality and contraception, it was perhaps considered a taboo within the family. Many programs and workshops, including joint shopping, have also focused on the importance of money management and saving.

Through the project, mentees received musical instruments, tablets, booklets, books, clothes, bikes to help with school integration and interest in learning.

One of the main goals of mentoring is to encourage further education and to develop the girls' vision. In order to achieve this goal, it was necessary to convince the parents, which proved to be a much more difficult task than the attitude of the girls.

They organized career guidance sessions for girls, took them to different places where they could meet different professions, and attended school visits: high schools, universities and colleges; where they were introduced to different life paths, they were offered options.

The involvement of families also played an important role in mentoring, they could participate in joint events and organize family days. Typical for mentees is that there are many single-parent and multi-child models, multi-generational families at risk of unemployment. For many mentees, 
the family maintainer is also unemployed, and illiteracy can also occur. Many generations live in the same apartment; the private sphere cannot be solved. There were convicted offenders in the family and many mentors also became victims of crime.

\subsection{Mentees}

In order to evaluate the mentoring activity, we conducted an online questionnaire with the mentees in November 2019. The number of respondents was 431, which is nearly 20 percent of those affected.

The girls were satisfied with the mentoring program. It is not typical to drop out of the program because girls are happy to attend. Where dropouts occurred, it was due to relocation, family problems, and guardianship.

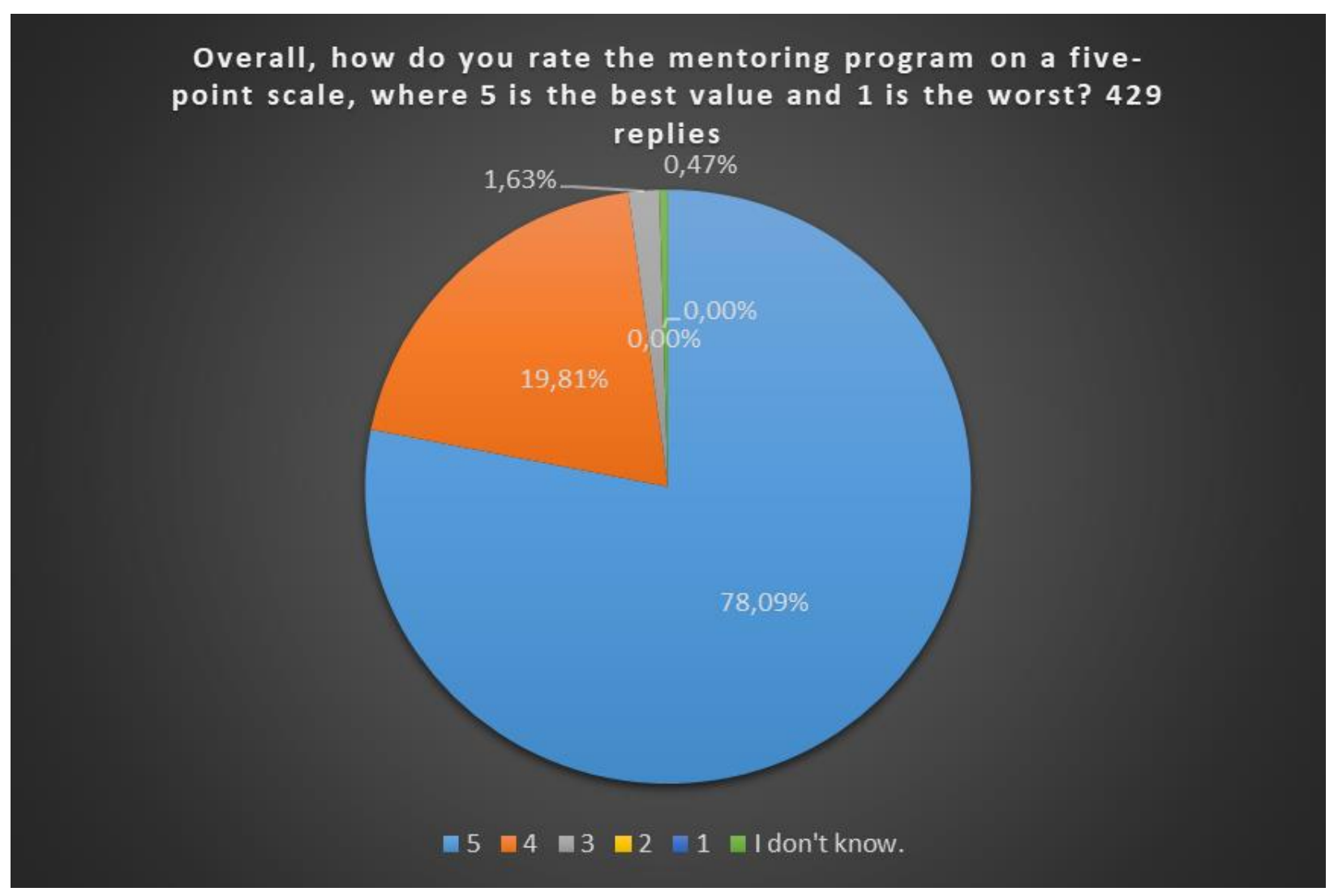

4. figure: Girls' Questionnaire: Evaluation of Mentoring Program; Source: Author, Hungarian Educational Authority

There was no negative answer to the question of how they felt about participating in the mentoring program overall. The scores of 1 and 2 representing the lower end of the scale were not marked by the respondents. The work of the mentors was acknowledged by the girls and considered to be helpful, who could be accessed through electronic interfaces (e-mail, facebook, skype, viber, etc.) were available. The mentors were able to make the meetings interesting, the 
mentoring activities were also successful in that they could reflect on the importance of continuing to educate girls, gaining new insights into family and female roles, and learning many new things about Roma culture.

There were 317 responses to the open question "What was your most memorable experience about mentoring, you were either grateful, or thoughtful, or surprised". The vast majority of the answers are about excursions, leisure activities, and there are also common discussions, career choices, learning about Roma culture and tradition.

The explicit aim of the mentoring program was to develop communication skills and personality development, and the success of the mentoring program is proved by the fact that $3 / 4$ of the respondents were very willing to answer this question.

Girls reported several experiences:

"Food"

"They talk to me a lot, they listen to me and I think I'm important."

"I also got answers to questions that I couldn't discuss with anyone. For example, menstruation, sex."

"We have talked about the effects of photos uploaded to Facebook; and then we have discussed it with our family members. "

"I heard the Roma anthem here for the first time, and about the Roma Holocaust."

"I could trust my mentor, they gave us many good programs."

"I received a lot of attention and love."

"I talk to my mother more"

"We always did something during the conversation, so I dissolved. it was good to know a lot about myself, my adolescent behavior, and finally they didn't yell at me. They often quarrel with me at home."

"If my mentor doesn't push, I probably wouldn't go to school anymore. After all, I'm grateful that she didn't allow me to do that.

"I've met many adults who have shared with us the results of their lives so far. And they have confirmed that we will continue to learn."

"Roma role models who started from the same place as us and worked hard to reach their goal."

"The most memorable and defining moment was when we were visited by Roma young students as role models in a University. That's when I really thought it was worth learning, and I want to be part of such a community in the future."

"My confidence increased and I became more motivated. I have an idea of my future. It made me realize that I am the same as my age, there is no shame in me."

"It was amazing how much I was good at so many things."

\subsection{Mentors}

Mentor selection criteria

Mentor selection criteria included:

- experience in career selection and further training;

- continuing education, SEN, previous experience with disadvantaged learners; 
- teachers dealing with Roma children;

- Roma woman graduated from high school;

- be young;

- come from the local Roma community;

- be local and / or well informed in the locality;

- have experience as a foster parent.

Mentors could apply voluntarily, and organizations also contacted educators, leaders and social workers in educational institutions.

At the beginning of the project, the mentors also had to get to know each other so they could work together in a team.

To support the work of the mentors, organizations consider the supervision to be necessary and useful. Mentors can share a lot of things during the supervision, discuss with mentors, and report on their successes and problems. There are places where this is combined with monthly closures, meeting task schedules, and elsewhere there is monitoring every 3 months. Other organizations tend to find it helpful to discuss the case and if the mentor overcomes a problem, they will occasionally supervise or involve a psychologist.

\section{Mentors' opinion - focus group study}

Two focus group studies were conducted among the mentoring organizations. The first with guided questions in April 2019, the second in September 2019 with group discussions, better understanding and discussion of each other's experiences.

Focus group interviews revealed that the organizations applied for the Bari Shej program primarily because the project is part of an organization profile and seeks every opportunity to increase the chances of many disadvantaged students in the community to reduce poverty and promote further education, and even more support for families. Organizations have reported that they have good cooperation with the Roma municipality, are mutually supportive and have the opportunity to engage Roma mentors who can serve as role models for the target group.

Towards the end of the project, some mentors shared what they thought they had received from the program as a mentor:

György: He discovered Burn-out Syndrome. The program gave György a new impetus. Seeing the girls progress and knowing that what he was doing was rewarding his work.

Bianka: As she is only 21, her personality has undergone many changes. He has also become more motivated and needs to break out of the environment that is best achieved through learning / further education. It feels good to help others. Through the Bari Shej program, Bianka also got to places she couldn't afford.

László: Changing attitudes - how different women are than men. Female mentors treat girls differently than men, admire the activities of their female mentors, and the close relationship they have with girls. He thinks he had a harder time working as a man, because they look at the world differently, he's on the team like an uncle at the head.

Ildikó: It felt very good to be able to steer the children in the right direction and to take responsibility for them. As a school principal, it was good to be involved in other activities as well. She had met many precious people she had only ever heard of.

Melinda: Besides personality development, it meant professional development for her. Not only did she participate in the program as a mentor, but from the administration she also had 
professional leadership. In this unfamiliar terrain, it was difficult to get everything right (financially, professionally, in the best interests of the child). She is very grateful that at the right time she always mett people who helped her activities.

Marianna: Regardless of it was the first time she worked as a mentor, she thinks she was successful. She considered her mentors to be her own children, so she thought she had 5 children (she had 2 toddlers at home). It was a challenge for her as she dripped into the lives and families of 3 teenage girls who had completely different lifestyles. In his opinion, she had been able to establish a kind of trusting relationship with the parents because they shared with her what problems they had at home. She is glad that her mentor colleagues have welcomed her as a beginner. She learned a lot from them, she could always count on them.

The key to the success of the projects is professionally and humanly well-trained mentors. The key is to build trust. Mentors need to be patient, persistent, consistent, and show empathy. Collaboration with parents is also essential for success. A mentor who is open, accepting, and affectionate to her mentees also becomes a role model. Credibility, knowledge of local conditions, preparedness, planning for a longer period and common discussion of problems are also important factors.

However, the involvement of parents has been difficult, typically involving them through Gypsy traditions and meal programs, or by presenting Gypsy professions that parents practice. It has been a good practice to have a parent playing a central role in the community, and after successful involvement and commitment, more people joined. The parents were contacted separately, in some cases it was more effective. Other times it was helpful if the mentor did not initiate but waited for the parents to inquire or ask something.

The mentors went to the families, got to know the parents, and had several family visits. Others were able to get their involvement through joint events, health screenings for parents, cultural events and other events where the whole family was invited.

In many cases, the problem has been that parents do not allow girls to go for a day trips. They are being over-protected because of the Roma superstitions such as bus accident, it is considered safer at home.

Not only the lifestyle of the girls but also of their families shows the positive effects of the program (for example, in relation to the toiletries). Mental hygiene professionals gave lectures to girls on a variety of topics (such as toiletries, sex life, sexual defense). The previous topics affected the girls sensitively, the families did not educate them, so they were very aloof. The mentors were initially afraid of the repercussions of this, as this is a taboo subject in the Roma culture, but there was no feedback from parents that they would not like to allow their girls for such performances.

In general, the parent has been made aware that the program is in their best interests and that of their child. Parents believed that mentors would take care of their daughters. They talked with the mentor what the child needed, what to buy, and often these items keep the mentee and her family in the program.

Some families found it difficult to co-operate. Some families have been able to build deep trust, but others have been less successful. The families mentioned later misunderstood the project. It was thought that the mentors would focus on improving the learning outcomes.

Mentors believe that parent support and a positive attitude are essential to the success of the program.

\subsection{School principals and class leader teachers}


The schools are open to the Bari Shej program, and the class leader teachers and other teachers often ask the girls what excursions and trainings they were, they have motivated the girls to attend regularly in the program. Teachers have become much more receptive to this project - they think that "these little girls are finally doing something" - working with mentors to get girls to continue their learning.

In November 2019 (around this time most of the organizations completed the project or completed the project within a month or two), we sent an online questionnaire for girls' school principals and class leader teachers who all had experienced a positive change in the behavior of the students concerned.

Have you experienced any change in the behavior of the girls participating in the mentoring program?

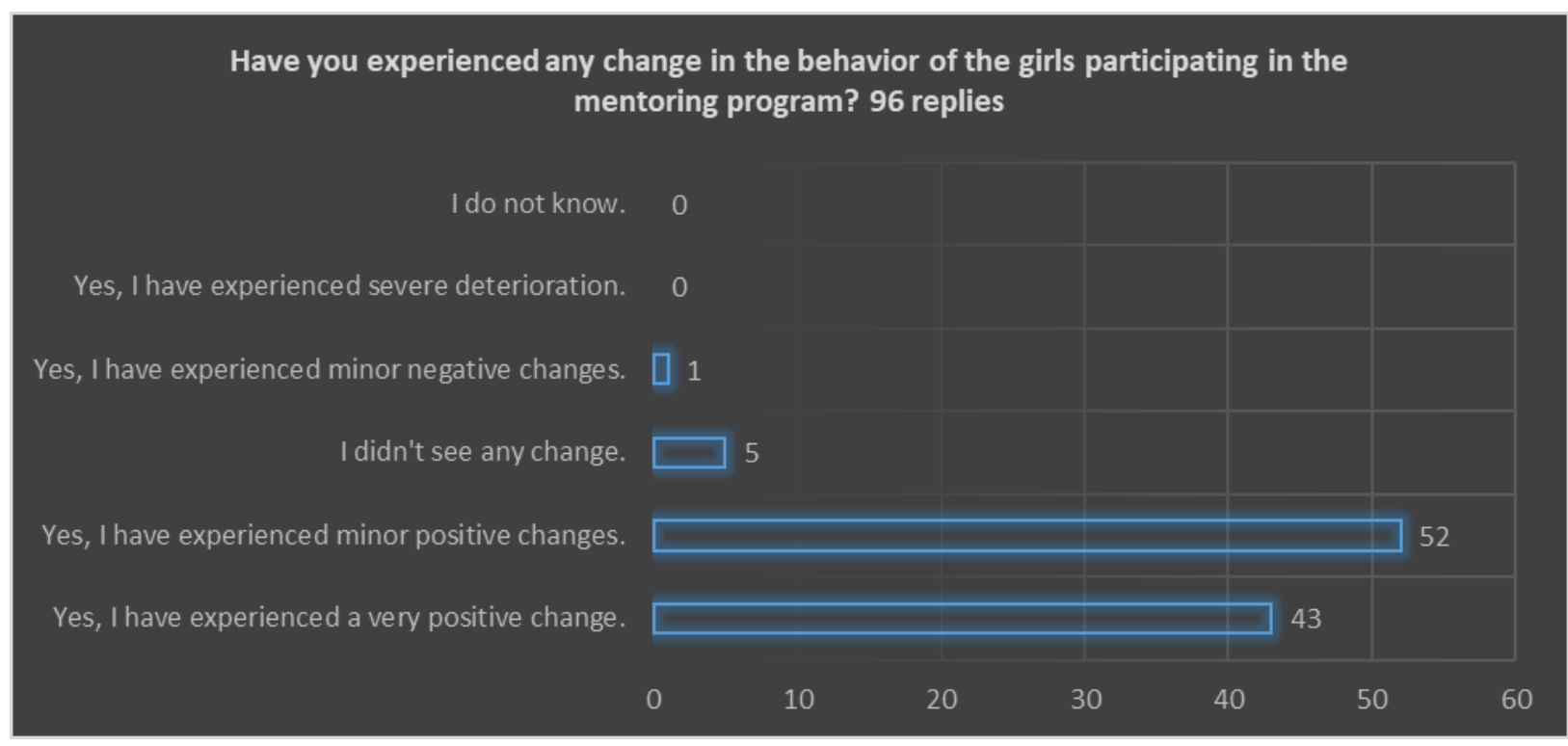

\section{5. figure: School principals and class leader teachers' views on the change in the behavior of girls participating in the mentoring program; Source: Author, Hungarian Educational Authority}

Respondents reported that the mentees most changed their behavior, became more disciplined, behaved with greater respect, and also improved their social skills and expressiveness.

\section{Summary of Bari Shej's mentoring system}

The mentors created another supportive, trusting environment, similar to the security family, where the girls' personality was further developed.

Through mentoring, mentors contributed to the girls' experiences of their integration, communication, career, life management, conflict management, and motivational skills. These experiences have highlighted the opportunities they have in their life.

Overall, the girls' questionnaire survey found that the girls found the mentoring to be useful, enriched with many experiences, and expressed that they felt they had developed through this help. 
Monthly data provided by mentors indicate that the most positive changes occurred in selfknowledge, communication skills and behavioral culture.

Mentors wanted to help reduce school drop-out rates by changing attitudes, creating a desire for learning, strengthening motivation and introducing new opportunities.

Many mentors provide examples of positive personality development. They find that mentees are more open to others and to new knowledge; they can talk about more and more topics; they dare to ask, they are more honest, more communicative, calm and have a positive vision.

The development of self-knowledge is also one of the positive examples, including positive selfimage, realistic body image and skill development, and becoming more self-confident. They dare to stand up for their own interests. They recognize their strengths and weaknesses; they are pretty much aware of where they need to develop. Mentees are able to recognize their own problems and seek help, and are more critical of themselves. They began to appreciate their potential, their self-confidence and self-esteem developed.

The mentored girls have become more sensitive to each other's problems, trying to help each other. Their cooperation skills increased, and attention to each other increased. Their relationship with adults and their peers has improved. They show greater respect for the mentor. They strive to adhere to the daily general rules of conduct. They are also developing socially, going to mentoring meetings in clean and tidy clothes and arriving on time.

Based on the monthly report of the mentors, it can be stated that the mentored girls have become more responsible, they recognize their learning obligations, take their work more seriously, keep more of their promises, are more committed, show more autonomy in life, and take responsibility.

The activities of the project do not primarily consist of tutoring, catching up, but the implementation of mentoring also contributes to the success of the mentees at school. They pay more attention to the lesson, learning is easier for them, and they ask for help in learning. They participated in several tasks and community work and competitions. The absenteeism of mentees has diminished. The motivation for learning increased among mentees, they understood the importance of learning, and strengthened their belief in the future and learning; a clearer and more positive vision has emerged.

The girls' interest in continuing education has increased and they are eager to participate in discussions on these issues. Various programs on career choice were provided, and the mentees' career ideas could be strengthened during the programs. The meetings with the invited persons and the visits were successful and successful programs were implemented. They showed very curious and respectful behavior during their career orientation activity.

The vast majority of organizations are planning follow-up. In two or three years' time, mentors expect, first and foremost, that girls will not be dropped out of school and will continue their education. In addition, they are counting on other positive effects that can result from the development of social skills due to a change in attitudes.

The organizations also stated what they considered to be the biggest failure of the project and what solution they considered appropriate. In particular, external factors were noted as shortness of project implementation time and difficulties in attitudes of families, which were not always changed.

The short time has been a problem for project implementation because confidence has already been established and the foundations need to continue to work in order to produce measurable results in the long term so that there is no downturn. Due to the success of the career guidance, time has been tight and interest is being created, but the time for further education has not yet come for some of the mentees, but the project has already been completed. 
Another external factor of failure is distrustful families, which could not be resolved. Many have mentioned that this difficulty, caused by family resistance or passivity, is a pattern that is difficult to change for girls. According to the traditional family model, the girl has a place at home. Cultural programs that are organized outside the institution's walls would be very useful, but they are not very willing to let go, especially for unaccompanied girls.

There have also been many cases of early school leaving due to pregnancy, and some have reported that some participants and their families were motivated solely by benefits in kind and also abused by their parents, such as selling a tablet, bicycle; lack of responsibility, showed a negative moral pattern to others.

Mentors wanted to help reduce school drop-out rates by changing attitudes, creating a desire for learning, strengthening motivation and introducing new opportunities.

The main aim of the Bari Shej project is to develop mentor-mentored relationships, the results of which shape the vision and self-image of Roma girls. The collection of reports, focus group surveys, questionnaires and good practices has shown that this objective is being achieved.

The mentors managed to establish good relationships with the girls and their families, the girls became more purposeful, their vision was strengthened, they were given effective guidance in their career orientation, their academic results improved with many mentees, and absenteeism decreased. Both the girls and the mentors agreed that they would find it useful to continue the program and to participate in it.

The mentors hope that this program will also have a positive impact on the children of the mentored girls by transferring what they have learned and educating them accordingly.

The boys are constantly asking when they will have such a program.

Instead of a final summary, here are some good tips from project implementing organizations for those with similar activities:

"Those who do similar activities need to know that they need to be patient and be satisfied with the success of small steps."

"Understanding with the family the importance of learning! Better involve families in joint programs! "

"Feel free to get involved because it's a great experience for mentors, mentees."

"The program has a lot of potential, but the realization depends on the mentor. The mentor is at the center of the program, so his or her selection is key."

\section{Acknowledgements}

I would like to thank my colleagues at the Hungarian Educational Authority who helped me to collect and process the data used. The study is part of EFOP-3.1.7-16-2016-00001 - Creating Opportunities in Public Education project. 


\section{References}

Aiello, E.; Amador-López, J.; Munté-Pascual, A.; Sordé-Martí, T. (2019) Grassroots Roma Women Organizing for Social Change: A Study of the Impact of 'Roma Women Student Gatherings'. Sustainability 2019, 11, 4054. https://doi.org/10.3390/su11154054

Bari Shej program call for proposals: https://www.palyazat.gov.hu/efop-144-17-bari-shej-nagylny-ft-mr\#

Creating Opportunities in Public Education project program guide: https://www.palyazat.gov.hu/efop-31716-eslyteremts-a-kznevelsben

Battaglia - Chabé-Ferret - Lebedinski (2017): Battaglia, Marianna and Chabé-Ferret, Bastien and Lebedinski, Lara: Segregation and Fertility: The Case of the Roma in Serbia. IZA Discussion Paper No. 10929. Available at SSRN: https://ssrn.com/abstract=3029799

Brüggemann - Friedman (2017), Christiana Brüggeman - Eben Friedman: The Decade of Roma Inclusion: Origins, Actors, and Legacies, European Education 49(1), 1-9, January 2017. [cited 2020 January 08] Available from: https://doi.org/10.1080/10564934.2017.1290422

Declaration (2005): Declaration of the Decade of Roma Inclusion 2005-2015, Sofia, Bulgaria, February 2 , 2005

European Commission (2019) Communication from the Commission to the European Parliament and the Council: Report on the implementation of national Roma integration strategies - 2019 \{SWD(2019) 320 final\} [cited 2020 Jan 05] Available from: https://eur-lex.europa.eu/legalcontent/EN/TXT/PDF/?uri=CELEX:52019DC0406\&from=FR

European Commission (2011). Communication from the Commission to the European Parliament, the Council, the European Economic and Social Committee and the Committee of the Regions: An EU Framework for National Roma Integration Strategies up to 2020. Brussels: European Commission; 2011 [cited 2020 Jan 08]. Available from: https://eur-lex.europa.eu/legalcontent/EN/TXT/PDF/?uri=CELEX:52011DC0173\&from=EN

Factsheet (2019): 2019 Report on National Roma Integration Strategies: Key Conclusions, Factsheet 2019 September, [cited 2020 Jan 08] Available from: https://ec.europa.eu/info/sites/info/files/factsheet roma integration strategies report 2019.pdf

FRA (2017) European Union Agency For Fundamental Rights: Second European Union Minorities and Discrimination Survey Questionnaire 2016, [cited 2020 Jan 08] Available from: https://fra.europa.eu/sites/default/files/fra uploads/fra-2017-eu-midis-ii-questionnaire en.pdf

Hajdú - Kertesi - Kézdi (2019): Tamás Hajdu \& Gábor Kertesi \& Gábor Kézdi: Health Differences between Roma and non-Roma Children in Hungary: Long-run Trends and Decomposition, Population and Development Review, The Population Council, Inc., vol. 45(3), pages 631-657, September 2019. https://doi.org/10.1111/padr.12276

Hotchkiss (2016), D.R., Godha, D., Gage, A.J. et al. Risk factors associated with the practice of child marriage among Roma girls in Serbia. BMC Int Health Hum Rights 16, 6 (2016) doi:10.1186/s12914016-0081-3

Hungarian Central Statistical Office (2018): Mikrocenzus 2016., 12. Nemzetiségi adatok, [Micro-census. Nationality http://www.ksh.hu/docs/hun/xftp/idoszaki/mikrocenzus2016/mikrocenzus 2016 12.pdf

Kyuchukov (2011) Hristo Kyuchukov: Roma girls: between traditional values and educational aspirations, Intercultural Education, v22 n1 p97-104 2011. https://doi.org/10.1080/14675986.2011.549648

Lauritzen - Nodeland (2018): Solvor M. Lauritzen and Tuva S. Nodeland: What is the problem represented to be?" Two decades of research on Roma and education in Europe, Educational Research Review, 10.1016/j.edurev.2018.04.002, 24, (148-169).

Rauh (2018): Christopher Rauh: Decomposing Gaps between Roma and Non-Roma in Romania, Journal of Demographic Economics, 84(2), 209-229. Cambridge University Press: 14 May 2018. https://doi.org/10.1017/dem.2017.19

Sárváry (2019): Attila Sárváry, Zsigmond Kósa, Renáta Erdei Jávorné, Anikó Gyulai, Péter Takács, János Sándor, Andrea Sárváry, Ágnes Németh, Réka Halmai, Róza Ádány: Socioeconomic status, health related behaviour, and self-rated health of children living in Roma settlements in Hungary, Cent Eur J Public Health 2019, 27(1):24-31. https://doi.org/10.21101/cejph.a4726

Statisztikai Tükör 2015/82: A hazai nemzetiségek demográfiai jellemzői, [Demographic characteristics of Hungarian nationalities] http://www.ksh.hu/docs/hun/xftp/stattukor/nemzetiseg demografia.pdf 